\title{
Management Accounting in Russian Companies: Analysis of Practices by Company Size and Industry Group
}

\author{
Pavel Lebedev ${ }^{1, *}$ \\ ${ }^{1}$ IEDC Bled School of Management, Postgraduate Studies, Prešernova cesta 33, 4260 Bled, Slovenia
}

\begin{abstract}
.
Research background: The paper extends previous reports [1, 2] providing detailed analysis of the state of management accounting practices in Russian mid-sized companies.

Purpose of the article: This study investigates the state of management accounting practices in Russian mid-sized companies.

Methods: Data was collected by means of survey. It is a qualitative study of interpretive and exploratory nature.

Findings \& Value added: The study demonstrated that bigger companies have more advanced level of management accounting. The integrated management accounting score - a measure developed in this study to assess the state of management accounting in a company - was lowest in the group of the "small" mid-sized companies and the highest in the group of the largest "mid-sized" companies, while "medium" mid-sized companies scored in between taking the closest position to the average of the whole sample. Analysis by industry group revealed that the level of management accounting is more advanced among manufacturing and trade companies, while the companies from construction \& engineering, transportation and services industries significantly lag behind.
\end{abstract}

Keywords: management accounting; controlling; Russia; emerging markets; survey-based study

JEL Classification: $L 20 ; M 41 ; M 49 ; O 52$

\section{Introduction}

This study is an extension of the survey-based study recently conducted by the author $[1,2]$. The survey method is one of the most frequently used approaches in management accounting research [3,4]. The initial study aimed to address the following research questions:

- What is the current state of management accounting practices (MAPs) in midsized private Russian companies?

\footnotetext{
*Corresponding author: p.lebedev@inbox.ru
} 
- How does the current state of MAPs in Russian companies compare to the best practices described in the Global Management Accounting Principles (GMAP) [5]? Are Russian MAPs consistent overall with the principles declared by the GMAP? Do they support each other?

- How do the MAPs in use contribute to the overall success of Russian companies?

The volume of data collected over the course of the study, along with limited analytical resources early in the project, called for additional data mining to develop new insights. Accordingly, this paper expands on the first stage of the study by looking into the details of the current state of MAPs in a range of company sizes and industry groups to perform a separate assessment and compare results from the within the datamined sets to the original dataset. The paper provides additional disclosures on the collected data in terms of the structure of the studied companies (breakdowns by size, industry grouping, number of questionnaires per company of specific type) to provide additional context.

\section{Method}

The project followed a five-stage framework $[6,7,8]$ adapted for survey-based studies conducted in the context of emerging markets to provide a basis for the research project's management, planning, and successful implementation. The detailed discussion of the research method is presented in the earlier publications $[1,2,7]$. It is suggested that usage of management accounting is not only lower, but also different in SMEs compared to larger entities [9] and has its own specifics in the countries, representing emerging economies [10, 11]. To account for this, the study is an exploratory, interpretive review, conducted with the aim of understanding management accounting in emerging markets, as viewed in the context of Russia, and formulating theoretical propositions about aspects of management accounting in mid-sized companies in the emerging market context.

The survey was administered to practicing managers representing financial functions of Russian mid-sized companies as they participated in corporate and open-enrolment professional development programs. In total, 756 representatives of financial and management accounting departments from 231 companies were surveyed. 522 questionnaires representing 167 companies were considered valid for processing.

Survey-based research is dependent on the degree to which the measures used capture the constructs that they are intended to represent $[12,13]$. The comprehensive questionnaire contained 14 subsections corresponding to each of the MAPs as described by the Global Management Accounting Principles [6]. Each subsection was divided into four parts, corresponding to the four principles of management accounting. In each part, statements of best practice for using the principles of the respective MAP were suggested and respondents were asked to rate the extent to which the practices were applied in their companies on a Likert scale. Average scores and the integrated scores were calculated for each MAP and principle of management accounting. For each respective area of practice, this indicates the state and intensity of management accounting practices. For each respective management accounting principle, a score indicates the extent to which management accounting principles are applied across MAPs and the extent to which MAPs realize the principles of management accounting. The results obtained were compared to the maximum possible score corresponding to the "best-practice case". This comprises a potential score of 70 for each management accounting principle, as each one can potentially be applied to each of 14 MAPs with a respective maximum score of 5. Likewise, there is a possible score of 20 for each MAP, as four management accounting principles can potentially enforce each MAP with a maximum score of 5 per principle. 
At the first stage of the project, the survey data was aggregated and average scores for all responses were compiled and interpreted, including averaged management accounting integrated scores. The current phase of the project extends the analysis to address specific differences in management accounting practices of the companies across size and industry group.

Companies with revenues of one to ten billion rubles (RUB) (15 to 156 million euros at an official rate of the Russian Central Bank as of 01.01.2017, at which time 1 EUR = 63,8111 RUB) were initially included in the scope of the study, as this corresponds to the classification that leading Russian banks use to determine mid-sized companies [1]. At the current stage of the study they are divided into three groups, representing "small" mid-sized companies (with revenues up to RUB2 bn), "medium" mid-sized companies (with revenues of RUB2-8 bn), and "large" mid-sized companies (with revenues of RUB8-10 bn), per metrics used by leading banks, hereafter referred to as small, medium, and large companies for the sample.

The study sorts companies into the following industry groups: manufacturing, trade, construction \& engineering, transportation services and other. This industry grouping provides a meaningful breakdown of data, while not imposing constraints on the resources needed to conduct the analysis. Table 1 provides the summary of the companies studied by industry group and size (respective number of companies).

Table 1. Surveyed companies by size (number of companies).

\begin{tabular}{|c|c|c|c|c|}
\hline \multirow{2}{*}{ Industry } & \multicolumn{3}{|c|}{ Annual revenue, RUB } & \multirow{2}{*}{ Total } \\
\cline { 2 - 4 } & $\begin{array}{c}\text { less than } \mathbf{2} \\
\text { bn }\end{array}$ & $\begin{array}{c}\mathbf{2} \text { bn }-\mathbf{8} \\
\text { bn }\end{array}$ & $\begin{array}{c}\text { more than 8 } \\
\text { bn }\end{array}$ & \\
\hline Manufacturing & 14 & 16 & 6 & $\mathbf{3 6}$ \\
\hline Trade & 29 & 15 & 9 & $\mathbf{5 3}$ \\
\hline Construction \& Engineering & 4 & 5 & 5 & $\mathbf{1 4}$ \\
\hline Transportation & 8 & 3 & 2 & $\mathbf{1 3}$ \\
\hline Services & 24 & 9 & 6 & $\mathbf{3 9}$ \\
\hline Other & 8 & 3 & 1 & $\mathbf{1 2}$ \\
\hline Total & $\mathbf{8 7}$ & $\mathbf{5 1}$ & $\mathbf{2 9}$ & $\mathbf{1 6 7}$ \\
\hline
\end{tabular}

Table 2 provides data on the number of questionnaires per company category by industry and size.

Table 2. Surveyed companies by size (number of questionnaires).

\begin{tabular}{|c|c|c|c|c|}
\hline \multirow{2}{*}{ Industry } & \multicolumn{3}{|c|}{ Annual revenue, RUB } & \multirow{2}{*}{ Total } \\
\cline { 2 - 4 } & less than $\mathbf{2}$ bn & $\mathbf{2}$ bn $\mathbf{- 8}$ bn & more than 8 bn & \\
\hline Manufacturing & 34 & 57 & 21 & 112 \\
\hline Trade & 64 & 80 & 32 & 176 \\
\hline Construction \& Engineering & 11 & 21 & 9 & 41 \\
\hline Transportation & 33 & 7 & 3 & 43 \\
\hline Services & 39 & 61 & 19 & 119 \\
\hline Other & 20 & 10 & 1 & 31 \\
\hline Total & 201 & 236 & 85 & 522 \\
\hline
\end{tabular}

Besides providing perspective on the phenomena under study, the breakdown of the data addresses concerns of comments raised during discussions of preliminary findings. These concerns relate to the possible influence of results of individual companies on results for the whole sample. The method to address this concern would be either to create average scores for each company across all survey questions and compare these results with the scores reported for the whole sample or else ensure that the average number of questionnaires per category is comparable. While the first approach would be more precise, 
at the current stage the second approach was more feasible. As Table 3 demonstrates, the average number of questionnaires per company computed for all companies is 3.13 and the average number of questionnaires per company and industry group is within range. There is a slight overweighting of medium mid-sized companies with an average of 4.63 and a lower average for the smaller mid-sized companies of 2.31. This provides context for data analysis and interpretation, emphasizing the overall focus on mid-sized companies.

Table 3. Surveyed companies by size (average number of questionnaires per company).

\begin{tabular}{|c|c|c|c|c|}
\hline \multirow{2}{*}{ Industry } & \multicolumn{3}{|c|}{ Annual revenue, RUB } & \multirow{2}{*}{$\begin{array}{c}\text { Average per } \\
\text { company }\end{array}$} \\
\cline { 2 - 4 } & $\begin{array}{c}\text { less than 2 } \\
\text { bn }\end{array}$ & $\begin{array}{c}\mathbf{2} \text { bn }-\mathbf{8} \\
\text { bn }\end{array}$ & $\begin{array}{c}\text { more than 8 } \\
\text { bn }\end{array}$ & 3.11 \\
\hline Manufacturing & 2.43 & 3.56 & 3.50 & 3.32 \\
\hline Trade & 2.21 & 5.33 & 3.56 & 2.93 \\
\hline $\begin{array}{c}\text { Construction \& } \\
\text { Engineering }\end{array}$ & 2.75 & 4.20 & 1.80 & 3.31 \\
\hline Transportation & 4.13 & 2.33 & 1.50 & 3.05 \\
\hline Services & 1.63 & 6.78 & 3.17 & 2.58 \\
\hline Other & 2.50 & 3.33 & 1.00 & 3.13 \\
\hline Average per company & 2.31 & 4.63 & 2.93 & \\
\hline
\end{tabular}

\section{Findings}

\subsection{Analysis of data by company size}

The analysis revealed that the state of management accounting as determined by integrated score is positively related to the size of the company determined by its revenues. With an average integrated score for the whole sample of 65 rounded to an integer, the group of smallest companies with revenues less than RUB2 bn has an integrated management accounting score of 56.32, while the median group of companies with revenues ranging from RUB2-8 bn has a score of 67.84 , while the group of the largest companies with revenues above RUB8 bn score at 76.4, out of a possible score of 280 that would be the "reference model" state of management accounting in a hypothetical company where all MAPs realize all management accounting principles in full.

The abovementioned distribution of management accounting integrated scores across the groupings of companies by size is explained by the increase in the average intensity of all MAPs with company size of the with exception of practices price and discount decisions, project management and risk management. These have a slightly higher value for the respective score for the companies with revenues ranging from RUB2-8 bn.

In principle, the intensity of MAPs for the companies ranked by revenue in the middle range (RUB2-8 bn) corresponds to the average company profile for the whole sample. The only notable exception is MAP strategic tax management with a score of 2.96 compared to the average score of 4 (rounded to an integer).

Due to the rounding at the initial stage of the study, the average scores for the practices risk management, internal control and internal audit were reported as 0 . However, the actual values range between 0 and 0.49 across companies. Thus, the more detailed representations provide insignificant score values for these MAPs.

Table 4 presents the data arranged to demonstrate the extent to which MAPs reflect the accounting principles for the three groups of companies. The breakdown of the integrated score by principles of management accounting again demonstrates that the bigger the company in terms of revenue, the higher quality of management accounting it has, as 
evidenced by the increase of the score for each of the principles moving from the smallest to the biggest companies.

The extent to which MAPs reflect management accounting principles across the companies, ranged by revenues in the middle (RUB 2 bn - 8 bn), corresponds to the average company profile for the whole sample.

Table 4. Management accounting score by company size: the extent to which MAPs reflect management accounting principles.

\begin{tabular}{|c|c|c|c|c|}
\hline \multirow{2}{*}{$\begin{array}{l}\text { Management accounting } \\
\text { principles }\end{array}$} & \multicolumn{3}{|c|}{$\begin{array}{l}\text { Management accounting score for companies with } \\
\text { annual revenue, RUB }\end{array}$} & \multirow[t]{2}{*}{$\begin{array}{c}\text { Avera } \\
\text { ge }\end{array}$} \\
\hline & less than 2 bn & 2 bn -8 bn & more than 8 bn & \\
\hline Communication & 18.55 & 22.78 & 26.03 & 22.00 \\
\hline Information & 18.88 & 23.01 & 26.04 & 22.00 \\
\hline Value & 6.61 & 8.76 & 9.49 & 8.00 \\
\hline Stewardship & 12.28 & 13.29 & 14.84 & 13.00 \\
\hline Integrated score & 56.32 & 67.84 & 76.40 & 65.00 \\
\hline
\end{tabular}

As has been noted, the analysis demonstrates the increase in aggregated average integrated scores with the lowest values applying to the companies with revenues of less than RUB2 bn, middle values for companies with revenues ranging from RUB2 to 8 bn, and the highest values for companies with revenues higher than RUB8 bn. However, the more detailed analysis looking at MAPs across each of the four of the management accounting principles reveals some exceptions. These exceptions assume that in some cases the score for the separate MAPs of the bigger company would be lower than the respective score of the company that represents the entire group of companies with lower revenues. In spite of the fact that these differences are offset in the total results, they may lead to inferences about the state of management accounting in the studied companies. The main irregularities in intensity dynamics of MAPs of the companies differentiated by size may be summarized by the following points worth noting.

The contribution of MAP price, discount, and product decisions to the management accounting principle information is relevant is significantly higher across the companies in the middle revenue range, as compared with the other groups.

The contribution of MAP project management to the management accounting principle impact on value is analysed is significantly higher across companies in the middle revenue range, as compared with the other groups.

The contribution of MAP investment appraisal to the management accounting principle stewardship builds trust is significantly lower across the companies in the middle revenue range, as compared with the other groups.

The contribution of MAPs management and budgetary control, resource management, price, discount, and product decisions, strategic tax management and internal control to the management accounting principle impact on value is analysed is the lowest across companies in the middle revenue range, as compared with the other groups.

The contribution of MAPs cost transformation and management, price, discount, and product decisions, treasury and cash management, financial strategy and risk management to the management accounting principle stewardship builds trust is the lowest across the biggest companies, as compared with the other groups.

\subsection{Analysis of data by industry groups}

Analysis of data arranged by industry groups demonstrates two noticeable trends. First, the overall management accounting level and intensity is strongest within manufacturing and trade companies, with integrated management accounting scores respectively at 68.73 and 
66.46, above the average score of 65 (rounded to an integer). Second, while other industry groups all lag significantly behind, the transportation industry has the worst management accounting score at 59.43 .

In principle, the intensity of MAPs for the companies representing the trade industry corresponds to the average company profile for the whole sample. The only notable exception is MAP strategic tax management with a score of 2.97 compared to the average score of 4 (rounded to an integer).

Table 5 below presents the breakdown by industry.

Table 5. Management accounting score by industry group: the state and intensity of MAPs.

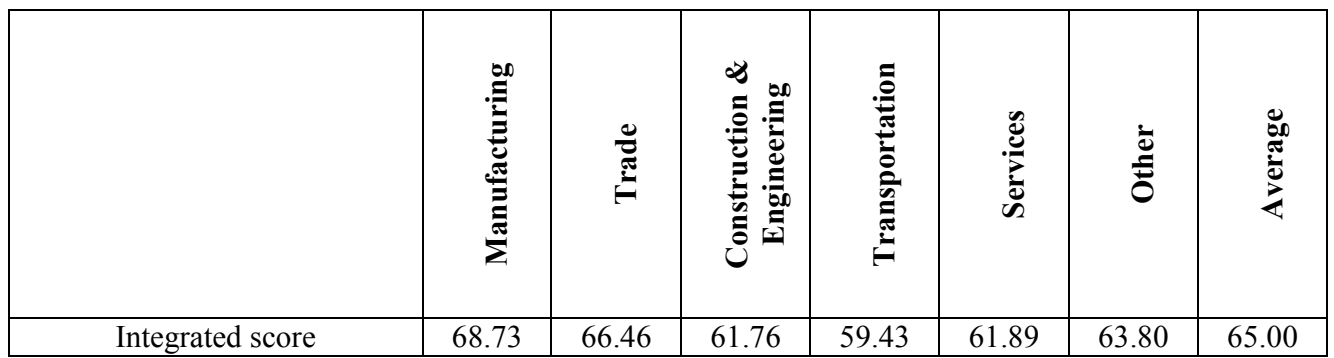

Table 6 presents the data arranged to demonstrate the extent to which MAPs reflect management accounting principles for the companies by industry group. The breakdown of the integrated score by principles of management accounting again demonstrates that the overall management accounting state and intensity is the strongest within manufacturing and trade companies across all four management accounting principles, while other industries lag behind, with the transportation industry showing the worst results demonstrated.

In general, the extent to which MAPs reflect management accounting principles across companies in the trade industry corresponds to the average company profile for the whole sample.

Table 6. Management accounting score by industry: the extent to which MAPs reflect management accounting principles.

\begin{tabular}{|c|c|c|c|c|c|c|c|}
\hline 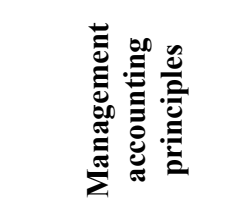 & 葛 & 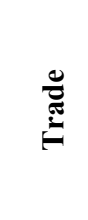 & 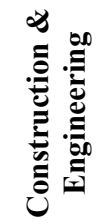 & 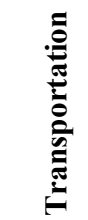 & 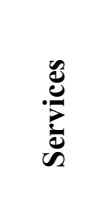 & 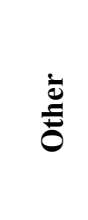 & 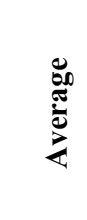 \\
\hline Communication & 23.38 & 21.91 & 20.24 & 19.76 & 21.05 & 21.23 & 22.00 \\
\hline Information & 23.06 & 22.59 & 21.14 & 20.34 & 20.72 & 21.71 & 22.00 \\
\hline Value & 8.57 & 8.44 & 7.96 & 7.30 & 7.38 & 7.73 & 8.00 \\
\hline Stewardship & 13.72 & 13.52 & 12.42 & 12.03 & 12.74 & 13.13 & 13.00 \\
\hline Integrated score & 68.73 & 66.46 & 61.76 & 59.43 & 61.89 & 63.80 & 65.00 \\
\hline
\end{tabular}

\section{Discussion}

The detailed analysis in this paper, conducted as a subsequent stage of the initial study $[1,2]$ confirmed the initial findings and provided additional perspectives on the state of management accounting in Russian companies. 
Breakdown of data by company size reveals trends similar to medium mid-sized companies being at the closest position to an average case (67.84 vs 65.00$)$. The profile of the biggest companies turned out to be better as evidenced by higher integrated management accounting score (76.40) and the profile of the smallest companies was lower (56.32). The positive dynamics of the integrated score and accordingly better quality of management accounting observed from smaller to bigger companies can be explained by the following factors: a) improvement of management practices as a result of implementing professional management to facilitate a transfer from a small sole proprietorship to growing company; b) a need to attract capital to finance growth and corresponding need to comply with stricter rules of corporate governance including improvement of information and reporting systems; c) regional growth of companies assuming more complex internal information and reporting systems, requiring an update of the financial function and thus attracting better skills and processes into the company.

Breakdown of data by industry group demonstrates that the overall management accounting state and intensity is the strongest within manufacturing and trade companies (integrated score respectively 68.73 and 66.46), with the companies from construction \& engineering, and transportation and services industries lagging significantly behind. This can be explained by the following factors: a) manufacturing and trade companies are numerous; their practices are easier to standardize and adopt industry-wide; b) they are overall more regulated than companies in other sectors, and these two industries can be said to be more mature, leading to unified management practices; c) manufacturing and trade are traditionally more professionalized and share a common body of knowledge; d) companies from the construction and engineering, and transportation and service industries in Russia function largely in the "gray" economy with fewer professional management tools in place and more idiosyncratic practices.

\section{Conclusion}

This study confirms findings about the state of management accounting in Russian midsized companies obtained at the initial phase of the research project. It provides extensions and insights through a breakdown of data and added perspectives applied at the subsequent stage of the study. The study demonstrates that bigger companies have more advanced levels of management accounting. The integrated management accounting score is a measure developed in this study to assess the state of management accounting in a company. It was lowest in the group of the smaller mid-sized companies and highest in the group of the largest mid-sized companies, while medium mid-sized companies scored in between, taking the closest position to the average of the whole sample. Analysis by industry group revealed that the level of management accounting is more advanced among manufacturing and trade companies, while the companies from construction and engineering, and transportation and services industries lag significantly.

The study contributes to the theory of management accounting by filling a gap in knowledge of specifics of management accounting beyond the industrialized international environment, namely in the context of emerging economies as exemplified by Russia. There is little internationally published research on management accounting in Russia. This report adds to the international body of accounting literature and facilitates academic conversations among the world-wide scientific community.

For further investigations, researchers should consider case studies as a future research strategy $[14,15]$ to contextualize the findings from survey studies with immediate experience from companies. As this study was limited to the mid-sized companies, further research could be expanded to include companies of different sizes and types (e.g. with varying ownership structure, non-commercial, deeper analysis of industries etc.). Future 
studies could also be extended to include the perspectives of other similar countries and provide comparisons of the state of management accounting in other emerging economies. Further studies on the impact of management accounting on corporate performance are also needed. Given the social nature of management accounting [16], they should focus on finding the role of management accounting in a sequence of causes and effects impacting corporate profits and stakeholder value and consider non-financial approaches based on a management accounting maturity model.

\section{References}

1. Lebedev, P. (2018). Management accounting in Russian mid-sized companies: results of an extended survey-based study. Proceedings of the $18^{\text {th }}$ International Scientific Conference Globalization and Its Socio-Economic Consequences (pp. 1196-1203). Rajecke Teplice, University of Zilina.

2. Lebedev, P. (2019). Management accounting practices in mid-sized companies in emerging economies: An evidence from Russia. In J. Kopec \& M. Bogusz (Eds.), Knowledge-Economy-Society: Challenges for Contemporary Economies - Global, Regional, Network and Organizational Perspectives (pp. 93-103). Torun: Cracow University of Economics.

3. Hiebl, M. R. W., Richter, J. F. (2018). Response rates in management accounting survey research. Journal of Management Accounting Research, 30(2), 59-79.

4. Speklé, R. F., Widener, S. K. (2020). Insights on the use of surveys to study management control systems. Accounting, Organizations and Society, 101184.

5. The Chartered Institute of Management Accountants. (2014). Global management accounting principles.

6. Brownell, P. (1995). Research methods in management accounting. Coopers \& Lybrand and Accounting Association of Australia and New Zealand.

7. Lebedev, P. (2015). Getting insight into management accounting and control systems: a framework for survey-based research design for emerging markets context. Procedia-Social and Behavioral Sciences, 213, 293-298.

8. Smith, M. (2003). Research Method in Accounting.

9. Lavia López, O., Hiebl, M. R. W. (2015). Management accounting in small and medium-sized enterprises: Current knowledge and avenues for further research. Journal of Management Accounting Research, 27(1), 81-119.

10. Ezzamel, M., Xiao, J. Z. (2011). Accounting in transitional and emerging market economies. European Accounting Review, 20(4), 625-637.

11. Guilding, C., Cravens, K. S., Tayles, M. (2000). An international comparison of strategic management accounting practices. Management Accounting Research, 11(1), 113-135.

12. Bedford, D. S., Speklé, R. F. (2018). Construct validity in survey-based management accounting and control research. Journal of Management Accounting Research, 30(2), 23-58.

13. Scapens, R. W. (2006). Understanding management accounting practices: A personal journey. The British Accounting Review, 38(1), 1-30.

14. Modell, S. (2005). Triangulation between case study and survey methods in management accounting research: An assessment of validity implications. Management Accounting Research, 16(2), 231-254. 
15. Scapens, R. W. (1990). Researching management accounting practice: The role of case study methods. The British Accounting Review, 22(3), 259-281.

16. Vollmer, H. (2009). Management accounting as normal social science. Accounting, Organizations and Society, 34(1), 141-150. 